\title{
Hemicraniectomy for large middle cerebral artery territory infarction: outcome in 19 patients
}

\author{
M B Pranesh, S Dinesh Nayak, V Mathew, B Prakash, M Natarajan, V Rajmohan, \\ R Murali, A Pehlaj
}

Background: Large space-occupying middle cerebral artery infarction accounts for 10-15\% of all supratentorial infarctions and carries a mortality of $50 \%$ to $80 \%$. Hemicraniectomy may be useful when optimal medical management has failed.

Methods: Between June 1997 and June 2000, 19 patients who fulfilled the clinical and imaging criteria for large middle cerebral artery infarction underwent hemicraniectomy because of impending herniation despite best medical therapy. The National Institute of Health Stroke Scale (NIHSS) assessed neurological status on admission and at one week after surgery. At 3 month follow up, The Barthel Index (BI) and Rankin Scale (RS) were used to assess the functional outcome among survivors.

Results: There were 15 males and 4 females with a mean age of 46.5 years (range 27-76 years). Ten patients $(53 \%)$ had dominant hemisphere stroke. The mean interval between stroke onset and surgery was 60.3 hours (range 20-103 hours). The mean NIHSS score before surgery was 20.5 (range 17-26) and 10.5 (range 6-22) after surgery. One patient $(5.2 \%)$ died due to post-operative meningitis. At follow up, mean BI was 56.4 (range 25-90) and RS revealed severe handicap in 4 patients $(21 \%)$. Patients under 50 years of age had a significantly better outcome with mean $\mathrm{BI}$ of 60.7 as compared to only 41.3 $(p=<0.048)$ in older patients. Speech function, especially comprehension improved in all patients with dominant hemisphere infarction.

Conclusion: These findings add to previous studies suggesting hemicraniectomy may be a useful procedure in patients with large middle cerebral artery territory infarction. The functional outcome is good in younger patients. A randomised controlled trial is required to substantiate these findings.

M assive space-occupying middle cerebral artery (MCA) territory ischemic stroke is a well recognised entity and accounts for $10-15 \%$ of all supratentorial strokes. The syndrome usually affects younger adults, and they may have concomitant anterior cerebral artery (ACA) or posterior cerebral artery (PCA) territory involvement. It is characterised by hemiplegia, hemianopia, hemianaesthesia, hemineglect (in non-dominant hemisphere involvement), aphasia (in dominant hemisphere involvement), forced eye and head deviation, progressive deterioration in consciousness within first 2 days and, thereafter, unilateral pupillary dilatation indicating rostro-caudal herniation within 2-4 days. ${ }^{1}$ In a recent multicentre case control study of patients with large middle cerebral artery strokes admitted within 48 hours of symptom onset, the mortality due to brain oedema was $47 \%{ }^{2}$ Over the last two decades, several authors worldwide have shown that decompressive hemicraniectomy can not only be reduce mortality, but can also result in good functional outcome, especially in younger adults. ${ }^{3-10}$ Despite these encouraging results, hemicraniectomy has not gained widespread acceptance, especially in developing countries like India, where the incidence of stroke in the young is much higher than in the developed countries. ${ }^{11}$ We therefore report a series of patients with complete MCA territory ischemic stroke who underwent hemicraniectomy because they showed signs of transtentorial herniation despite appropriate medical therapy.

\section{SUBJECTS AND METHODS}

The Neurosciences department admits around 350 patients with cerebrovascular diseases of various etiologies. Between June 1997 and June 2000, 19 patients were selected for decompressive hemicraniectomy following progressive swelling after MCA occlusion. All patients had routine hematological and biochemical profile, ECG and trans-thoracic echocardiography, cranial CT scan, and Doppler studies of the extra-cranial cerebral vessels. None had significant co-morbid medical or neurological disease. The neurological status was measured on the National Institute of Health Stroke Scale $(\text { NIHSS })^{12}$ on admission. All patients received maximal medical management of intracranial hypertension and systemic support. Surgery was performed when there was evidence of transtentorial herniation. A wide fronto-temporo-parietal craniectomy was performed. The dura was incised but no duroplasty performed. Temporalis fascia was placed over the arachnoid overlying the dural defect. Infarcted brain tissue was not excised. Post-operatively, the patients were managed in the intensive care unit. The NIHSS scoring was repeated one week after surgery. Patients were assessed three months after surgery and the outcome was quantified on the Barthel Index $(\mathrm{BI})^{13}$ and the Rankin Scale (RS) ${ }^{14}$ Cranioplasty was done about three months after discharge.

\section{STATISTICAL ANALYSIS}

SPSS 10 for Windows package was used for statistical analysis. All values are expressed as means. Statistical dispersion is expressed as standard deviation. Kruskal-Wallis and MannWhitney non-parametric tests were used to compare means between groups. Statistical significance was assigned to $\mathrm{p}$ value of $<0.05$.

\section{RESULTS}

There were 19 patients, 15 males and 4 females, with mean age of 46.5 yrs (SD 11.8; range 27-76 yrs). Fifteen patients (79\%) were under 50 years of age. Ten patients $(53 \%)$ had left-sided

Abbreviations: ACA, anterior cerebral artery; MCA, middle cerebral artery; PCA, posterior cerebral artery 

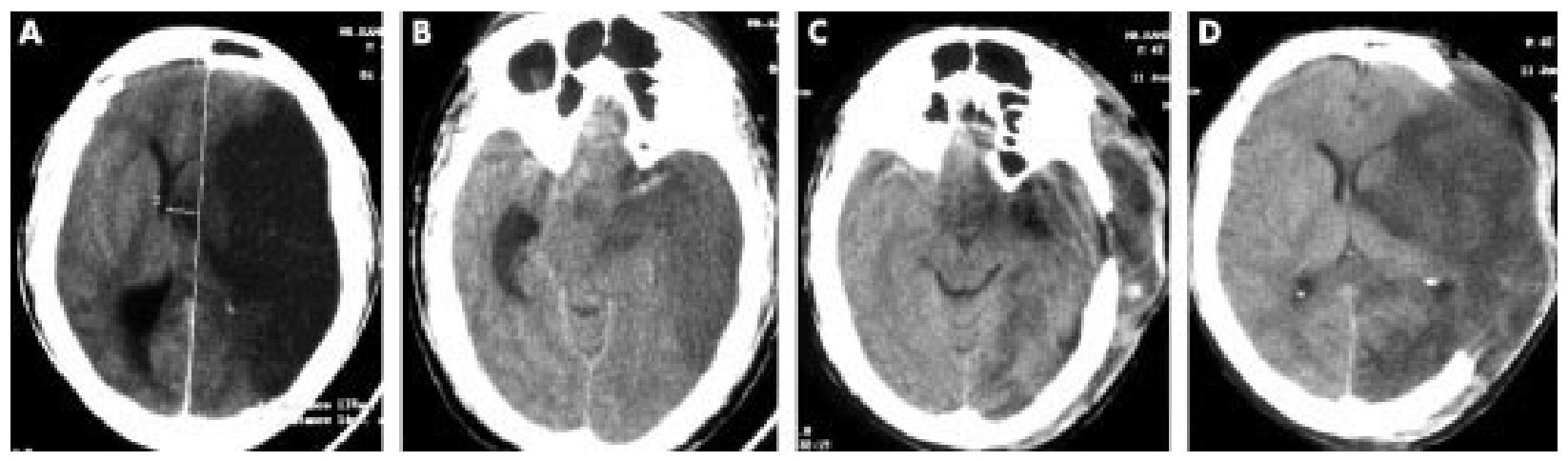

Figure 1 Serial non-contrast enhanced cranial CT scans of a patient before and after hemicraniectomy. (A) Large MCA territory infarction with $14 \mathrm{~mm}$ midline shift. (B) Shows effacement of the brainstem cisterns. Note the thrombosed MCA stem "hyperdense MCA" sign. (C, D) 7 days after hemicraniectomy. The infarcted tissue bulges through the craniectomy defect. The midline shift is now negligible and the brainstem cisterns are clearly visible.

hemicraniectomy while the rest had right-sided decompression. The mean interval between stroke-onset and admission to hospital was 25.3 hours (SD 26.8; range 1-100hrs). The mean interval between stroke-onset and decompressive surgery was 60.3hrs (SD 23.9; range 20-103 hrs). The mean NIHSS score prior to surgery was 20.5 (SD 2.6; range 17-26). The NIHSS score a week after surgery was 10.5 (SD 4; range 6-22). The mean duration of hospital stay was 35.3 days (SD 16; range 19-88 days). At 3 month follow up, the mean BI was 56.3 ( SD 19.2; median 55; range 25-90). The RS showed severe handicap in only $21 \%$, while the majority showed significant improvement. One patient $(5.2 \%)$ died due to post-operative meningitis. Among the patients with dominant hemisphere stroke, the speech function improved in most. We compared the duration of hospital stay, stroke onset to admission times, stroke onset to surgery time, NIHSS scores and BI among patients under 50 and those above 50 years of age. There were no significant differences between the groups for duration of hospital stay, stroke onset to admission time, stroke onset to decompressive surgery time, NIHSS scores or BI. The BI, however, was significantly higher (60.7; SD 18.9; median 57.5; range 30-90) for the below 50 years group as compared to 41.3 (SD 11.8; median 45; range 25-50) for the below 50 years group $(\mathrm{p}=<0.048)$.

\section{DISCUSSION}

We have described a series of patients with massive hemispherical infarction who underwent decompressive hemicraniectomy. The principal aim of surgery was to save life, since the majority $(79 \%)$ of them were under 50 years and did not have concomitant serious medical illness. Even though decompressive craniectomy for supratentorial infarction has been done in a few patients sporadically over four decades, it is only in the last two decades that the treatment has been studied systematically. ${ }^{35}$ A recent Cochrane review, however, has shown that there is no evidence from the extant literature of an evidence basis for the use of this procedure. ${ }^{16}$

Our study however, add to the previous findings that suggest both mortality and functional outcome may be better after surgery. This is supported by experimental data from rat models. ${ }^{17} 18$ Functional outcome is better in younger patients ${ }^{10} 19$ and when surgery is performed early in the course of the stroke. ${ }^{39}$ It has generally been felt that hemicraniectomy must be offered only to patients with non-dominant hemispherical strokes, the reason being that speech is unaffected and functional outcome would therefore be better. ${ }^{4-7}{ }^{10}$ Several studies have however reported good language recovery in some patients. ${ }^{38}$ We also found that all patients with aphasia had improved and could communicate usefully. Even though most had a degree of expressive dysphasia, they regained their ability to comprehend.

In our study, only one patient died (mortality rate 5.2\%), 50 days after surgery because of postoperative meningitis and abscess formation and not due to herniation. The mortality rates in various reports vary from $0 \%$ to $27 \%$ (see table 1 ). The problem with our study, like many studies, is that it is retrospective and may be subject to selection bias. Nevertheless, we have demonstrated that the procedure can be performed safely in our set up in a developing country.

We conclude that although hemicraniectomy can be very effective, randomised controlled trials are needed to properly evaluate its place in the management of patients with spaceoccupying hemispheric stroke.

Table 1 Studies on hemicraniectomy in space-occupying MCA infarction

\begin{tabular}{|c|c|c|c|c|c|c|}
\hline Author (ref no) & Year & No of patients & $\begin{array}{l}\text { Mean age } \\
\text { (years) }\end{array}$ & $\begin{array}{l}\text { Time to } \\
\text { surgery (hrs) }\end{array}$ & Mortality & Outcome \\
\hline Rengachary et al (4) & 1981 & 3 & 31 & 76 & 0 & 1 independent; 2 disabled \\
\hline Young et al (5) & 1982 & 1 & 59 & 18 & 0 & Independent \\
\hline Kondziolka \& Fazl (6) & 1988 & 5 & 40 & 52.8 & 0 & All independent \\
\hline Delashaw et al (7) & 1990 & 9 & 57 & 76.4 & 11 & 4 independent; 4 disabled \\
\hline Kalia \& Yonas (8) & 1993 & 4 & 34.3 & 60 & 0 & All independent \\
\hline Rieke et al (9) & 1995 & 32 (late surgery) & 48.8 & 39 & 34.4 & Mean $\mathrm{Bl} 62.6$ \\
\hline Carter et al (10) & 1997 & 14 & 49.2 & 98 & 21 & 8 independent; 3 disabled \\
\hline Schwab et al (3) & 1998 & 31 (early surgery) & 50.3 & 21 & 16 & Mean $\mathrm{BI} 68.8$ \\
\hline Schwab et $a^{*}(3)$ & 1998 & 63 (early plus late surgery) & 49.7 & 30 & 27 & Mean $\mathrm{Bl} 65$ \\
\hline Holtkamp et al (19) & 2001 & 12 & 64.9 & 42.4 & 33 & Mean $\mathrm{BI} 28.1$ \\
\hline Present study & 2003 & 19 & 46.5 & 60.3 & 5.2 & Mean $\mathrm{Bl} 56.3$ \\
\hline
\end{tabular}




\section{Authors' affiliations}

M B Pranesh, S Dinesh Nayak, V Mathew, B Prakash, V Rajmohan, R Murali, A Pehlaj, Department of Neurology, K.G.Hospital and

Postgraduate Medical Institute, Coimbatore, India

M Natarajan, Department of Neurosurgery, K.G.Hospital and

Postgraduate Medical Institute, Coimbatore, India

Correspondence to: Professor M B Pranesh, Ananda Nilaya, 5th Street Tatabad Coimbatore 641012 India; sdnayak62@hotmail.com

\section{REFERENCES}

1 Hacke W, Schwab S, Horn M, et al. Malignant middle cerebral artery infarction: clinical course and prognostic signs. Arch Neurol 1996:53:309-15

2 Kasner SE, Demchuk AM, Berrouschot J, et al. Predictors of fatal brain oedema in massive hemispheric ischemic stroke. Stroke 2001;32:2117-23

3 Schwab S, Steiner T, Aschoff A, et al. Early hemicraniectomy in patients with complete middle cerebral artery infarction. Stroke 1998;29:1888-93.

4 Rengachary SS, Batnitzky S, Morantz RA, et al. Hemicraniectomy for acute massive cerebral infarction. Neurosurgery 1981:8:321-8.

5 Young PH, Smith KJ, Dunn RC. Surgical decompression after cerebral hemispheric stroke: indications and patient selection. South Med J 1982;75:473-5

6 Kondziolka D, Fazl M. Functional recovery after decrompressive craniectomy for cerebral infarction. Neurosurgery 1988:23:143-7.

7 Delashaw JB, Broaddus WC, Kassel NF, et al. Treatment of right hemispheric cerebral infarction by hemicraniectomy. Stroke 1990;21:874-81.
8 Kalia KK, Yonas $\mathrm{H}$. An aggressive approach to massive middle cerebral artery infarction. Arch Neurol 1993;50:1293-7.

9 Rieke K, Schwab S, Krieger D, et al. Decompressive surgery in space-occupying hemispheric infarction: results of an open, prospective study. Crit Care Med 1995;23:1576-87.

10 Carter BS, Ogilvy CS, Candia CJ, et al. One-year outcome after decompressive surgery for massive nondominant hemispheric infarction. Neurosurgery 1997:40:1168-76.

11 Nayak SD, Nair MD, Radhakrishnan K, et al. Stroke in the young: clinical features and analysis of risk factors. Natl Med J India 1997; 10:107-12.

12 Brott TG, Adams HP, Olinger CP, et al. Measurement of acute cerebral infarction: a clinical examination scale. Stroke 1989:20:864-70.

13 Mahoney F, Barthel D. Functional evaluation: The Barthel Index. Md Med J 1965;14:61-65.

14 Rankin J. Cerebral vascular accidents in patients over the age of 60 : prognosis. Scott Med J 1957;2:200-15.

15 Schwab S, Rieke K, Aschoff A, et al. Hemicraniectomy in space-occupying hemispheric infarction: useful early intervention or desperate activism? Cerebrovasc Dis 1996:6:325-9.

16 Morley NC, Berge E, Cruz-Flores S, et al. Surgical decompression for cerebral oedema in acute ischaemic stroke. Cochrane Database Syst Rev 2002;(3):CD003435

17 Doerfler A, Forsting M, Reith W, et al. Decompressive craniectomy in a rat model of "malignant" cerebral hemispheric stroke: experimental support for an aggressive therapeutic approach. J Neurosurg $1996 \cdot 85 \cdot 853-9$.

18 Engelhorn T, Doerfler A, Kastrup A, et al. Decompressive craniectomy, reperfusion, or a combination for early treatment of acute "malignant" cerebral hemispheric stroke in rats? Potential mechanisms studied by MRI. Stroke 1999;30:1456-63.

19 Holtkamp M, Buchheim K, Unterberg A, et al. Hemicraniectomy in elderly patients with space occupying media infarction: improved survival but poor functional outcome. J Neurol Neurosurg Psychiatry $2001 ; 70: 226-8$

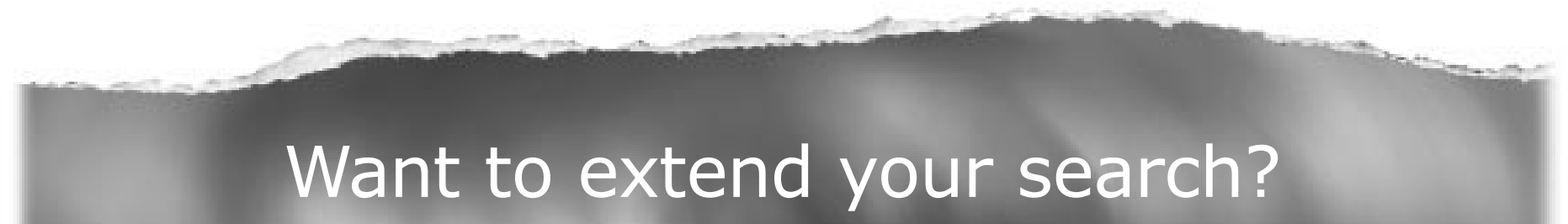

\section{Cross journal searching}

Can't find what you're looking for in Journal of Neurology, Neurosurgery, and Psychiatry? Extend your search across $340+$ journals. Search restriction options include specific subject areas (eg. clinical medicine, basic research), select specific journals or search all available titles.

\section{www.jnnp.com}

